\title{
On the Approach to Pricing of the Cloud SaaS Solutions with Focus on Marketing Solutions
}

\author{
Ondrej Matustik \\ Department of System Analysis, University of Economics, Prague, Czech Republic \\ ondrej.matustik@vse.cz
}

Keywords: SaaS; Cloud Computing; Pricing Model.

\begin{abstract}
The world of IT is changing towards to the cloud SaaS solutions. This change has several dimensions and we will focus in the article on the potential pricing models. Current models of license payment for the software obviously failed and the cloud SaaS providers are trying to find a new one. In the article we will compare currently possible models and will try to select the best one, especially for the marketing solutions.
\end{abstract}

\section{Introduction}

Software-as-a-Service is one of the key components of IT innovation nowadays. We can read almost every day about some new service provided as a SaaS from cloud, or about some significant investment by investments funds to some already existing services. Almost all services provided by standard "box" software are currently covered and offered by some SaaS cloud provider.

In this article we will understand with SaaS cloud provider abbreviation (or shortly SaaS) the Software-as-a-Service, which is provided only from the cloud environment. Some SaaS services can be provided by the dedicated box hosted at customers and we would like to avoid this situation, because there can be valid different pricing model.

SaaS has not so long history and there are predictions that this is future of the software. Therefore this is an important space for the research on various topics. In this article we will focus on possible pricing approaches and will try to determine the best pricing approach for SaaS.

\section{Related Research}

As the SaaS topic is quite new, it is hard to find an exhausting article focused on this topic. And therefore we decided to create this article. There is comprehensive research from Pacific Crest Securities [1], but this shows only percentage popularity of some SaaS pricing models without explanation.

Mathew and Nary [2] did some research on the main costs drivers in SaaS pricing, supported with statistical calculations, but we do not see the differences between pricing models here.

Kamra, et al [3] published article on the pricing model of cloud computing solutions, but in the fact he distinguish only static or dynamic pricing. As we will see further in this article, this split can be much more detailed. We can see some specific examples, i.e. from Pharmacy [4], but definitely there is a lot of space for further research.

\section{Differences between SaaS and Standard Software}

We can observe a lot of differences between standard "box" software and Software as a Services. For our article will be the most important the differences, which can impact pricing (so we will exclude comparison in user interface, etc.). So for the pricing differentiators we see mainly following differences:

- Operation mode - the box software has to be installed on the clients' environemnt and client has to secure operational environment + the operations engineers, who run the whole environments. Also the installation of the software is very different for both kinds of software. 
- Updates and maintenance - SaaS is usually operated by software provider, so updates and maintenance are fully covered by him. The box solution is usually upgraded very sporadically, or even without upgrades for some time.

- User support - due to the mode of operations, the users are expecting a different level of support. In the standard box software, it is usual that users are asking the internal IT at first, in comparison to the SaaS model, there is usually built in some support function or helpdesk provided directly by the SaaS provider.

There are also many more differences, but would like to show you only some of them. The main reason for this is that we are focused on the pricing and the costs related to the usage of SaaS:

- To prove that in the SaaS model, the software provider is responsible for many more activities, so the expectation that this software will be much cheaper is not fully valid.

- On the other side we can assume that the savings from scale will be significant on the side of the software provider too.

These two contradictory powers are very important influencers of the SaaS business. The SaaS provider has to convince the potential clients that SaaS software is not significantly cheaper than the standard box one. On the other side the provider had to reach out the economy of scale, otherwise will be not able to run the whole solution with expected profitability.

\section{SaaS Pricing Model}

As we can expect from the previous lines, there will be different pricing models for the usage of SaaS.

But first, let us remain the typical pricing models for the standard box solutions. We have at least following:

- User licence - typical licence of time limitedlunlimited usage per one computer or one named user.

- Concurrent user licenses - for the enterprise software, the second most typical licensing scheme is the number of concurrent user. The application is provided as the client-server architecture and server is responsible for managing the maximal number of concurrently running users.

- Flat fee licence - the organization can use the application on flat fee basis for the whole company.

Table 1: Difference between box software and SaaS.

\begin{tabular}{|l|l|l|}
\hline Difference & \multicolumn{1}{|c|}{ Box software } & \multicolumn{1}{|c|}{ SaaS } \\
\hline $\begin{array}{l}\text { Number of } \\
\text { users }\end{array}$ & $\begin{array}{l}\text { In many cases flat fee, no matter how many } \\
\text { users use the software, because the costs of } \\
\text { additional users bear the license owner }\end{array}$ & $\begin{array}{l}\text { Each user has to pay, because each user means } \\
\text { utilization of the service (either SW, HW or } \\
\text { related service). }\end{array}$ \\
\hline $\begin{array}{l}\text { Time } \\
\text { limitations }\end{array}$ & $\begin{array}{l}\text { The license is usually for unlimited time, or the } \\
\text { updates should be extra purchased, or are } \\
\text { included for limited period in basic license }\end{array}$ & $\begin{array}{l}\text { Because of the nature of "Service", the license is } \\
\text { timely limited and after expiration the user is not } \\
\text { allowed to use the software anymore. Usual } \\
\text { length of contract is 1 year. }\end{array}$ \\
\hline SLAs & $\begin{array}{l}\text { Because the solution of operated by the software } \\
\text { owner, usually no SLAs are guaranteed. }\end{array}$ & $\begin{array}{l}\text { At least in B2B should be SLAs guaranteed, usual } \\
\text { industry standard is 99,5\% of availability. }\end{array}$ \\
\hline $\begin{array}{l}\text { Scope of the } \\
\text { services }\end{array}$ & $\begin{array}{l}\text { The "service" is in many cases software only the } \\
\text { software itself + basic help. Everything else } \\
\text { (installation, configuration etc.) has to be paid as } \\
\text { extra. }\end{array}$ & $\begin{array}{l}\text { The customers expect full service - L1 or L2 } \\
\text { support, expert on retainer, customer success } \\
\text { team, developer portal and many others services. } \\
\text { And this should be usually included in the price. }\end{array}$ \\
\hline $\begin{array}{l}\text { Release } \\
\text { new version }\end{array}$ & $\begin{array}{l}\text { There are usually 1-2 releases/year, upgrade is in } \\
\text { many cases very difficult. }\end{array}$ & $\begin{array}{l}\text { Many vendors use continuous integration, with } \\
\text { almost daily upgrades. }\end{array}$ \\
\hline
\end{tabular}


Before we will go to the type of the licence, we would also like to stress more generally the differences between the standard box solutions and software as a service.

From the table above we can see, that there are big differences in the providing the software in the box and software as a service.

Let's take the overview of the pricing models from the Pacific Crest Survey [1]:

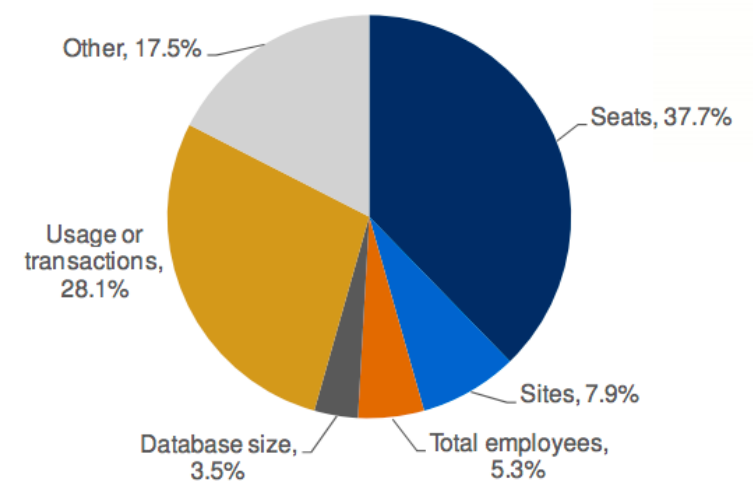

Figure 1 SaaS license models usage.

And now we would like to describe each model and compare the advantages and disadvantages:

Pricing per seat - According to the Pacific Crest survey [1], the most popular way of pricing the SaaS solution, which is used by almost $38 \%$ companies. The most typical representatives here are salesforce.com, box.com, Netsuite or Google Apps for Business.

Advantages here are mainly easy invoicing, clear overview of usage, clear pricing and possibility to offer bulk discounts.

Disadvantage is mainly the decision, how to set the prices. Because the SaaS provider has the costs related to the usage of product - R\&D, HW usage, maintenance and others, but the pricing is indirect. The customer does not pay for the usage, but pays for the seats. There is required to do a diligent calculation of real costs related to one seat sold. And obviously, this calculation is based on the averages, so the users, who are using the services more than average, are in the advantage. The SaaS provider can obviously protect himself by margin, but he need to take care about competition and their product margin. Second disadvantage of the seat pricing is fact that it is very easy comparable to the other vendors and services. The customers are asking, why they should pay much more for some specialized services, like CRM or BI, when they have almost everything from Google for as low as $5 \$$ a month.

We can state that pricing per seat is usually good for all SaaS, where the user have an active role and is not only viewer and when we can assume that the user activity will be the main source of system usage. This model is also suitable for the use cases, where the customer requires control over the costs.

Usage or transaction pricing is the second most popular model (and we can also include category Others from the Pacific Crest survey [1], because it contains very similar categories). Usage or transaction pricing is very straightforward, mainly in the transaction pricing part.

Advantages - clear invoicing based on the agreed metric, easy overview of the service consumption, clear price list for each used unit or transaction. Also for the provider there is clear link between the usage and price, so provider should not be in the risk of the overage usage.

We can also find some disadvantages. First is the fact that it is very hard for the customer to control the total cost. Some of the employees can overuse the service, which can result in the large invoices. So it is really necessary to closely monitor the usage of the service. Also the calculation can be sometimes misleading. It is necessary to take into the account the complexity of the SaaS application, because one unit of usage or one transaction in the SaaS application can be very different in comparison what we understand. So it is really good from the customers standpoint to 
clarify, what is meant by unit of usage of transaction, how many of those "units" do we need to perform one standard operation and what will be the final cost.

Total employees - total number of employees is usually used in the situations, when the solution has to be deployed company-wide, and thanks to the price of the product it makes no sense to distinguish each seat. Typical example can be Okta service.

The advantage is simplicity of the pricing in terms of the price.

Disadvantages are almost the same as seat pricing, because it is again about the usage of the product.

So this price structure is good in the situations with lower per seat price and company wide application.

Database size pricing - is useful pricing mainly for BI tools or other SaaS services, which are mainly depending on the database size. Currently Splunk uses it i.e.

The advantage of this pricing is clear overview and easiness of measurements. Also it is simple metric for the customer, because the customer can easily predict, how much data they have.

But this pricing has also some disadvantages - first of them is the decision, when we should measure the database size. Is it average during some period of time, or is it peak or lowest value in the defined time period? And also many applications are creating the caches, or even the way of the data storing can be very different, so the final size of the database can be much bigger in comparison to our initial thought.

So the database size pricing is useful in the situations, where the main cost driver is database and we can clearly explain the end-users our model and estimate the database size.

All the proposed pricing is based on the assumption that cost model depends mainly on the usage of the hardware and software provided. But when we would like to design a pricing scheme, we should not forget that there is also another part of the service - support and Operations. Are mainly for the smaller companies and companies with smaller amount of customers, the Support and Operations can be responsible for significant amount of the total costs. This should be covered in the margin, but definitely we recommend to do not omit these costs.

For the Marketing purposes. the per seat model is probably the best one. It is really hard to measure the transactions or database size in this case. The measurement of total employees does not make sense, beacause Marketing does not include whole company. And also taking into the account the typical Marketing SaaS operations (for details see [5]), the per seat model seems to be best fit.

\section{Conclusions}

Pricing of the SaaS solutions is very dynamically developing. The companies are trying to find the best model for the solution and also, what is more important, the best pricing level for selected model.

Thanks to the dynamic of development, we can expect big changes both in the pricing models and pricing levels in the future.

This article can serve as the solid base of the comparison between old "box" software pricing principles and new SaaS pricing principles and also as the guide for the starting SaaS companies, which pricing model should they use. The comparison of the pricing models is also important part of the article.

\section{Acknowledgements}

The research work was supported by Internal grant agency of University of Economics No. F4/18/2014.

\section{References}

[1] 2013 Pacific Crest Private SaaS Company Survey Results, Pacific Crest Securities. 
[2] Mathew, M., \& Nair, S. (2010). PRICING SAAS MODELS: PERCEPTIONS OF BUSINESS SERVICE PROVIDERS AND CLIENTS. Journal Of Services Research, 10(1), 51-68.

[3] Kamra, V., Sonawane, K., \& Alappanavar, P. (2012). CLOUD COMPUTING AND ITS PRICING SCHEMES.International Journal On Computer Science \& Engineering, 4(4), 577581.

[4] Farmacias Ahumada Improves Pricing via SaaS. (2008). Chain Store Age, 84(3), 62.

[5] SMUTNÝ, Zdeněk, ŘEZNÍČEK, Václav, PAVLÍČEK, Antonín. Measuring the Effects of Using Social Media in the Marketing Communications of the Company: Presentation of Research Results. In: 21st Interdisciplinary Information Management Talks (IDIMT 2013). Linz: Trauner Verlag, 2013, s. 175-178. ISBN 978-3-99033-083-8. 